\title{
Spectral Characterization, Dielectric, Mechanical and SHG Studies of Thiourea Doped L-Alanine Cadmium Chloride Crystals
}

\author{
M.Malathi ${ }^{1}$, S.L.Rayar ${ }^{2}$, P.Selvarajan ${ }^{3}$ \\ ${ }^{I}$ Department of Physics, Research centre, Scott Christian College (Autonomous), Nagercoil-629003, \\ Tamilnadu, India. \\ ${ }^{2}$ Department of Physcis, St.Jude's College, Thoothoor-629176, Tamilnadu, India. \\ ${ }^{3}$ Department of Physics, Aditanar College of Arts and Science, Tiruchendur- 628 216, Tamilnadu, India.
}

\begin{abstract}
L-alanine cadmium chloride (LACC) crystals doped with thiourea were grown by slow evaporation technique. The solubility of the samples were determined gravimetrically at various temperatures in the range $30-50^{\circ} \mathrm{C}$. Single crystals of thiourea doped L-alanine cadmium chloride were tested for the crystal structure by single crystal XRD studies. The values of SHG efficiency and laser damage threshold were determined for the samples. Dielectric constant and loss factor of the grown crystals were determined at different frequencies and temperatures. Microhardness and third order NLO parameters were measured for the samples. Spectral studies were carried out for the grown crystals and the results are presented.
\end{abstract}

Keywords: Metal organic crystal, doping, XRD, SHG, LDT, Dielectric, Hardness

\section{Introduction}

An amino acid mainly contains a carboxylic group and an amino group and the amino acids form the building blocks of the protein structure. In this work amino acid like L-alanine has been considered to prepare thiourea doped L-alanine cadmium chloride crystals. L-alanine is a nonessential amino acid which can be manufactured by the human body,and does not need to be obtained directly through the diet. Among the amino acids, L-alanine is the simplest acentric crystal and it is a naturally occurring chiral amino acid [1,2]. Efforts have been made on the amino acid mixed complex crystals in order to make them suitable for linear and nonlinear device applications. In amino acid based metal organic complexes, the organic ligand is usually more dominant in the NLO effect. As for the metallic part, focus is on the metals like $\mathrm{Zn}, \mathrm{Cd}$ and $\mathrm{Hg}$ as these compounds usually have a high transparency in the UV region, because of their closed $\mathrm{d}^{10}$ shell. Potential NLO materials [3] like bisthiourea cadmium chloride (BTCC), triallylthiourea cadmium chloride (TATCC) have been studied. The amino acids like L-arginine and L-histidine have been exploited for the formation of salts with different organic/ inorganic acids. As a result, semiorganic NLO materials such as L-arginine phosphate monohydrate, L-histidinetetrafluroborate have been synthesized and are found to be suitable in number of NLO applications [4,5]. Several new complexes incorporating the amino acid L-alanine have been recently crystallized and their structural, optical and thermal properties have been investigated [6-9]. L-alanine cadmium chloride was first synthesized by Kathleen et al. [10] and later its properties were studied by Dhanuskodi et al. [11]. Bright et al. have reported the frequency and temperature dependence of dielectric properties of L-alanine cadmium chloride [12]. Linear and nonlinear optical properties of L-alanine cadmium chloride were studied by Kalaiselvi et al. [13]. with varieties of dopants. To improve the various physical and chemical properties of LACC crystals, thiourea has been added as the dopant in this work. The aim of the work is to grow thiourea doped L-alanine cadmium chloride (LACC) crystals and to subject the grown crystals to various studies such as nucleation kinetic studies, XRD studies, UV-visible transmittance studies, SHG studies, laser damage threshold (LDT) studies and microhardness studies.

\section{Synthesis and growth}

To obtain thiourea doped LACC samples, L-alanine (99.5\% purity) and analar grade cadmium chloride monohydrate in the molar ratio of 1:1 were taken and dissolved in double distilled water. Then $5 \mathrm{wt} \%, 10 \mathrm{wt} \%$ and $15 \mathrm{wt} \%$ of thiourea were mixed with that solutions of LACC separately. The purity of the synthesized salts was further improved by re-crystallization process. Single crystals of thiourea doped LACC were grown by solution method with slow evaporation technique using the saturated solutions of the relevant synthesized salts. The saturated solutions of the salts were stirred well and were filtered and taken in beakers separately for crystallization. Over a period of 20-25 days, well faceted optically transparent seed crystals of various 
dimensions were collected. Good quality seed crystals were selected and were placed at the bottom of the beakers containing the solutions. The beakers were covered with perforated polythene papers and were kept in a vibration free platform at room temperature $\left(30^{\circ} \mathrm{C}\right)$ and the seed crystals grew into big-sized crystals. A constant temperature bath was used to maintain the constant growth temperature. The grown crystals are nonhygroscopic, stable, colourless and transparent. The grown crystals were subjected to various studies for the characterization.

\subsection{Solubility studies}

\section{Results and discussion}

The solubility studies of the grown crysytals were carried out by gravimetrical method at constant temperature bath [14]. The salt of the prepared sample was added step by step to $20 \mathrm{ml}$ of double distilled water in an air-tight container kept in the CTB and the stirring was continued till a small precipitate was formed at $30{ }^{\circ} \mathrm{C}$. Then, $5 \mathrm{ml}$ of the solution was pipetted out and taken in a petri dish and it was warmed up till the solvent was evaporated out. By measuring the amount of salt present in the petri dish, the solubility (in g/100 $\mathrm{ml}$ ) of the samples was determined. The same procedure was followed to find solubility of sample at other temperatures using the constant temperature bath. Figure 1 shows the solubility curve for thiourea doped LACC crystals. When LACC crystals are doped with thiourea, solubility is observed to be decreasing with increase of concentration of thiourea in the solution.

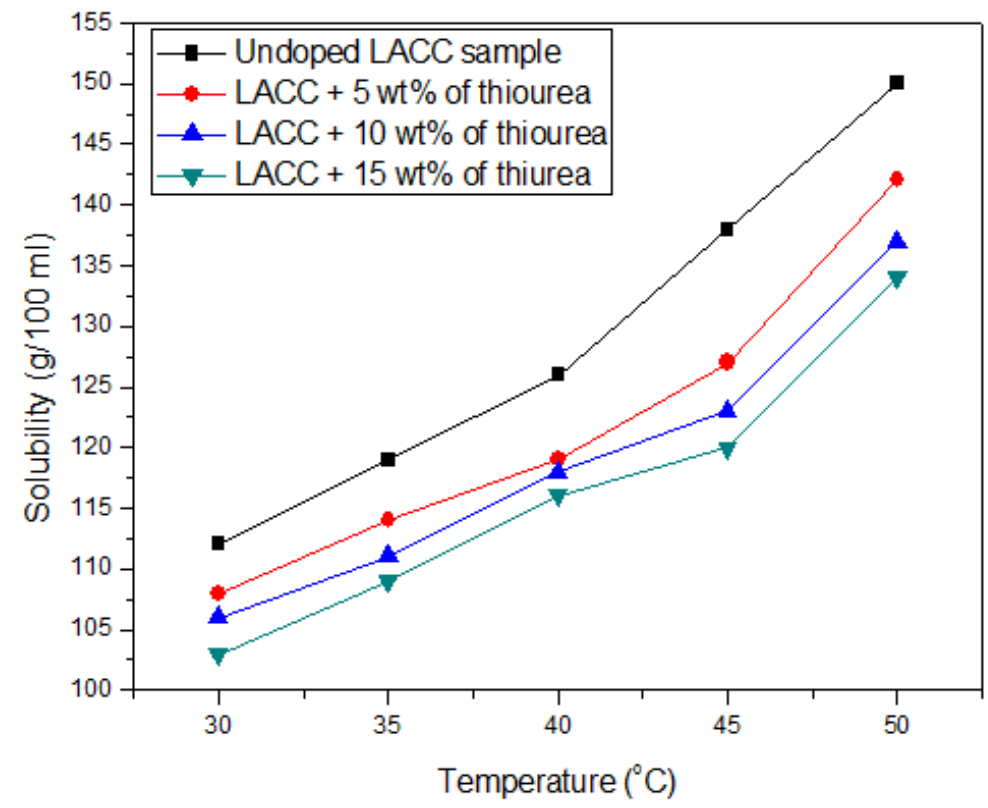

Fig.1: Solubility curves of undoped and thiourea doped L-alanine cadmium chloride (LACC) samples

\section{2 . Single crystal XRD studies}

The grown crystals were subjected to single crystal XRD studies using a single X-ray diffractometer (Bruker-Nonius MACH3/CAD4) and the lattice constants were obtained. The crystal structure of the undoped LACC crystal is found to be in good agreement with the reported literature [15]. Single crystals of thiourea doped L-alanine cadmium chloride were tested for the crystal structure by single crystal XRD studies and the obtained data are given in the table 1. From the data, it is revealed that the thiourea doped LACC crystals have monoclinic structure and the lattice constants are not altered much when LACC crystals are doped with thiourea. The space group for pure L-alanine cadmium chloride (LACC), thiourea doped LACC crystals is found to be $\mathrm{C} 2$ and it is a non-centrosymmetric space group. The differences in the values of lattice parameters between the pure and doped crystals are observed to be small and this observation confirms that the impurity molecules have not distorted the basic structure of the host crystals. 
Table 1: Unit cell constants of thiourea doped LACC crystals

\begin{tabular}{|c|c|c|}
\hline Sample & Unit cell constants & Volume of unit cell $(\square)^{3}$ \\
\hline $\begin{array}{c}\text { LACC crystal doped with } 5 \\
\text { wt } \% \text { of thiourea }\end{array}$ & $\begin{array}{c}\mathrm{a}=16.267(4) \AA \\
\mathrm{b}=7.293(3) \AA \\
\mathrm{c}=7.984(2) \AA \\
\alpha=90^{\circ} \\
\beta=114.35^{\circ} \\
\gamma=90^{\circ}\end{array}$ & $862.91(2)$ \\
\hline $\begin{array}{c}\text { LACC crystal doped with } 10 \\
\text { wt } \% \text { of thiourea }\end{array}$ & $\begin{array}{c}\mathrm{a}=16.310(2) \AA \dot{\alpha} \\
\mathrm{b}=7.285(4) \AA \\
\mathrm{c}=7.992(3) \AA \\
\alpha=90^{\circ}, \beta=113.47^{\circ} \\
\gamma=90^{\circ}\end{array}$ & $871.02(3)$ \\
\hline $\begin{array}{c}\text { LACC crystal doped with } 15 \\
\text { wt } \% \text { of thiourea }\end{array}$ & $\begin{array}{c}\mathrm{a}=16.295(3) \AA \\
\mathrm{b}=7.294(3) \AA \\
\mathrm{c}=7.894(1) \AA, \\
\alpha=90^{\circ}, \square \beta=112.87^{\circ} \\
\gamma=90^{\circ}\end{array}$ & $864.48(2)$ \\
\hline
\end{tabular}

\subsection{SHG Studies}

Second harmonic generation (SHG) is an important phenomenon in non-centrosymmetric crystals and it is a second-order NLO activity. The Kurtz-Perry powder technique was used to find the SHG efficiency of the samples[16]. SHG is confirmed by emission of green light from the sample $(\lambda=532 \mathrm{~nm})$ when the fundamental wavelength $(1064 \mathrm{~nm})$ from Nd:YAG laser is used. The input laser energy incident on the sample was $0.68 \mathrm{~J}$. The grown crystals of pure and thiourea doped L-alanine cadmium chloride were ground into powder form ( 200 $\mu \mathrm{m}$ of particle size) and for measuring Second Harmonic Generation (SHG) efficiency, Nd:YAG laser is directed onto the powdered sample. The emitted light is collected, filtered and detected with a photo multiplier tube. SHG is confirmed by emission of green light from the sample $(\lambda=532 \mathrm{~nm})$ when the fundamental wavelength $(1064 \mathrm{~nm})$ from Nd:YAG laser is used. The relative SHG efficiency for undoped and thiourea doped LACC samples are given in the table 2. From the results, it is observed that when LACC crystals are doped with thiourea, the values of SHG efficiency increase and found that thiourea doped LACC crystals are the better candidates for NLO applications.

Table 2: Values of SHG efficiency of the samples of thiourea doped L-alanine cadmium chloride

\begin{tabular}{|c|c|}
\hline Sample & Relative SHG efficiency Reference: KDP \\
\hline $\begin{array}{c}\text { Undoped LACC crystal } \\
\text { LACC crystal doped with 5 wt\% } \\
\text { of thioruea }\end{array}$ & 0.87 \\
\hline $\begin{array}{c}\text { LACC crystal doped with } 10 \\
\text { wt\% of thioruea }\end{array}$ & 0.95 \\
\hline $\begin{array}{c}\text { LACC crystal doped with } 15 \\
\text { wt\% of thiourea }\end{array}$ & 1.10 \\
\hline
\end{tabular}

\subsection{Laser Damage Threshold (LDT) studies}

Laser damage threshold (LDT) studies for the samples were carried out using an Nd:YAG laser (1064 $\mathrm{nm}, 18 \mathrm{~ns}$ pulse width). The energy of the laser beam was measured by Coherent energy/power meter (Model No. EPM 200). LDT value is determined using the formula $\mathrm{P}=\mathrm{E} / \tau \pi \mathrm{r}^{2}$ where $\tau$ is the pulse width in $\mathrm{ns}, \mathrm{E}$ is the input energy in $\mathrm{mJ}, \mathrm{r}$ is radius of the spot in $\mathrm{mm}$ [17]. The LDT value is one of the important device related properties of NLO crystals. LDT value is the maximum permissible power that can withstand in a particular crystal. The obtained values of LDT of the thiourea doped LACC crystals are given in the table 3 . From the results, it is observed that the values of laser damage threshold are low for the thiourea doped LACC crystals than that of undoped LACC crystal. The values of LDT for grown crystals are observed to be close to that of $\operatorname{KDP}\left(0.2 \mathrm{GW} / \mathrm{cm}^{2}\right)$ crystal [18]. 
Table 3: Values of laser damage threshold for thiourea doped L-alanine cadmium chloride samples

\begin{tabular}{|l|c|}
\hline \multicolumn{1}{|c|}{ Sample } & Values of LDT $\left(\mathrm{GW} / \mathrm{cm}^{2}\right)$ \\
\hline Undoped LACC crystal & 0.25 \\
\hline LACC crystal doped with $5 \mathrm{wt} \%$ of thiourea & 0.22 \\
\hline LACC crystal doped with $10 \mathrm{wt} \%$ of thiourea & 0.20 \\
\hline LACC crystal doped with $15 \mathrm{wt} \%$ of thiourea & 0.17 \\
\hline
\end{tabular}

\subsection{Dielectric parameters}

The dielectric constant and the dielectric loss factor are measured at different frequencies for various temperatures using a multi-frequency LCR meter. The temperature dependence of the dielectric constant and loss factor at frequencies $10^{3}$ and $10^{6} \mathrm{~Hz}$ for undoped and thiourea doped L-proline cadmium chloride crystals are presented in Figs. 2 and 3. It is observed that the dielectric constant and loss factor have high values at lower frequencies and are low at higher frequencies. The dielectric constant of the materials is due to the contribution of electronic, ionic, dipolar or orientation and a space charge polarization which is high relay upon on the frequencies. The space charge polarization is generally active at lower frequencies and high temperatures. The dielectric constant and loss factor are found to be increasing with increase in temperature. The low values of dielectric loss of the samples confirm the good quality of dielectric samples [19]. The results show that values of dielectric constant and loss factor of the LACC crystals are increased when they are doped with thiourea.
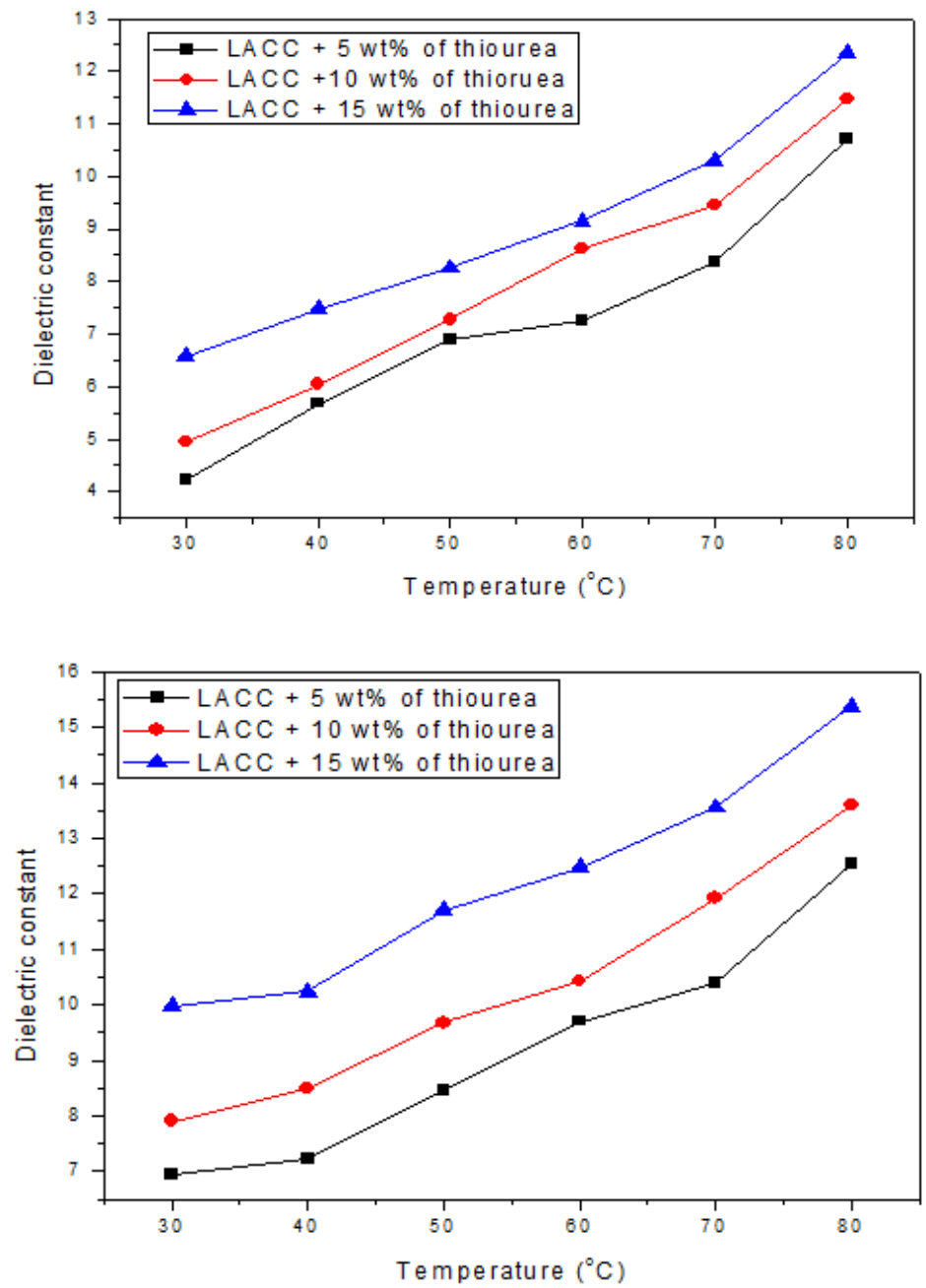

Fig.2: Temperature dependence of dielectric constant for thiourea doped LACC crystals at (a) $10^{3}$ and (b) $10^{6}$ $\mathrm{Hz}$. 

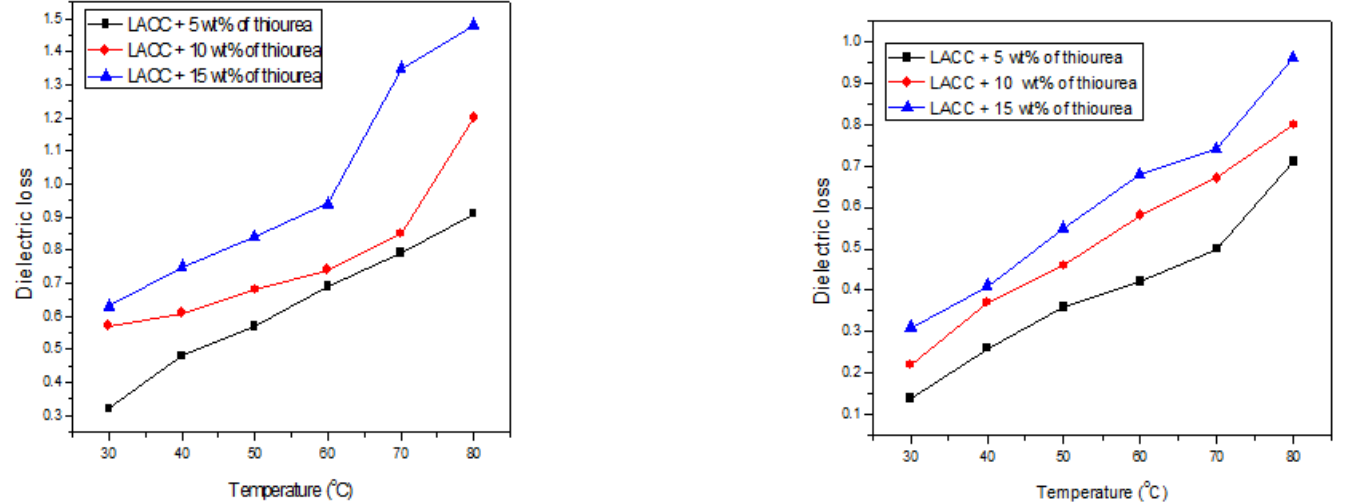

Fig.3: Temperature dependence of dielectric loss factor for thiourea doped LACC crystals at $10^{3}$ and $10^{6} \mathrm{~Hz}$.

\subsection{Microhardness studies}

The mechanical studies of the samples were made by Vickers hardness measurement at room temperature. Crystals, free from cracks, with flat and smooth surfaces were chosen for the static indentation tests. The crystal was mounted properly on the base of the microscope. Now, the selected faces were indented gently by loads varying from 25 to $100 \mathrm{~g}$ for a period of $10 \mathrm{~s}$ using Vickers diamond indenter attached to an incident ray research microscope. The Vickers hardness $\left(\mathrm{H}_{\mathrm{v}}\right)$ number at different loads were calculated using the following relation $\mathrm{H}_{\mathrm{v}}=1.8544 \mathrm{P} / \mathrm{d}^{2}$ where, ' $\mathrm{P}$ ' is the applied load in kilogram and ' $\mathrm{d}$ ' is the average diagonal length of the indentation marks in millimetre. The variation of hardness number with the applied load is plotted in the figure 4. It is noticed that the hardness is altered when LACC crystals are doped with thiourea and the changes in microhardness number may be due to the incorporation of impurities in the lattice of pure crystals.

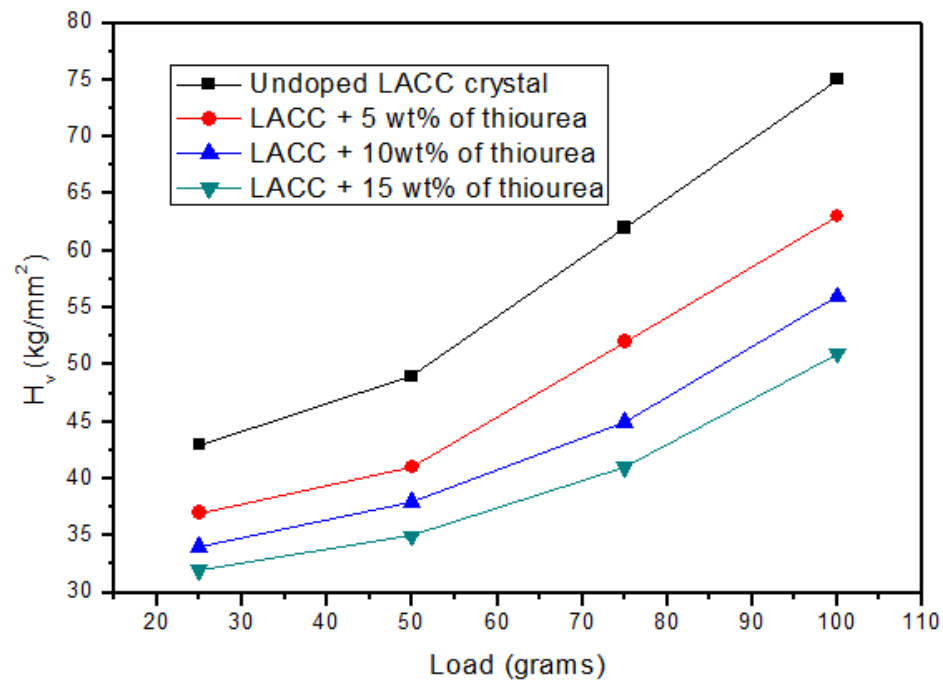

Fig. 4: Plots of microhardness number $\left(\mathrm{H}_{\mathrm{v}}\right)$ with the load for pure and thiourea doped LACC crystals

\subsection{Photoconductity studies}

The photoconductivity studies for the grown crystals were carried out by measuring dark and photo currents at different applied electric fields. The required current is noted for varying applied fields. The variations of dark and photo currents for thiourea doped LACC crystals are shown the figure 5. It is noticed that the values of dark current and photo current increase with increase of applied electric field. For all the samples, it is observed that the photo current is less than dark current and hence the samples have negative photoconductivity. The negative photoconductivity of the samples is due to reduction of charge carriers when light is passed onto the samples. The decrease in the mobile charge carriers during negative photoconductivity can be explained by the Stockmann model [20]. 


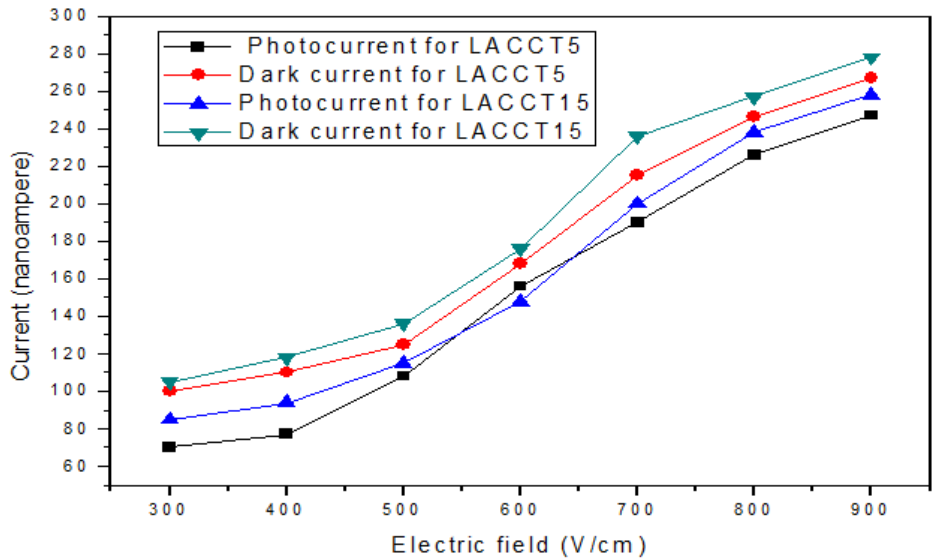

Fig. 5: Variations of photocurrent and dark current with the applied field for thiourea doped LACC (LACCT5 and LACCT10) crystals

\section{Conclusions}

Undoped and thiourea doped LACC crystals were grown by slow evaporation technique at room temperature. It is observed that the solubility has been altered when the samples are doped with thiourea. From the XRD studies, it is observed that undoped and thiourea doped LACC crystals crystallize in monoclinic structure and it is found that the incorporation of thiourea separately into the lattices of LACC crystals does not alter the crystal structure. The SHG efficiency of thiourea doped LACC crystals is measured with reference to that of KDP crystal. The dielectric constant and loss factor were measured for the samples at various frequencies and temperatures. The values of LDT are low for the thiourea doped LACC than that of undoped LACC crystal. The hardness of LACC crystals are observed to be altered when thiourea is added as the dopant into LACC crystal. The photoconductivity studies for the grown crystals were carried out by measuring dark and photo currents at different applied electric fields.

\section{Acknowledgement}

The authors would like to thank the staff members for their supported works from various research institutions such as Cochin University(Cochin), M.K. University(Madurai), M.S.University (Tirunelveli), St Joseph College (Trichy) and Crescent Engineering College (Chennai). Also the authors are thankful to the management of Aditanar College of Arts and Science, Tiruchendur, St.Jude's College, Thoothoor and Scott Christian College, Nagercoil for the encouragement given to us to carry out the research work.

\section{References}

[1]. Razzetti C., M. Ardoino, L.Zanotti, M.Zha, C.Parorici, Solution Growth and Characterization of L-alanine single crystals, Cryst. Res. Technol., (2002) 37, 456-465.

[2]. M. Jiang, Q. Fang, Adv. Mater. 11 (1999) 1147.

[3]. D. Eimerl, S. Velsko, L. Davis, F. Wang, G. Loicono, G. Kennedy, IEEE J. Quantum Electron. 25 (1989) 179.

[4]. S. Dhanuskodi, J. Ramajothi, Cryst. Res. Technol. 39 (2004) 592.

[5]. $\quad$ D.R. Babu, D. Jayaraman, R.M. Kumar, R. Jayavel, J. Crystal Growth 245(2002) 121.

[6]. R.Mohan Kumar, D.Rajan Babu, D.Jayaraman,R.Jayavel, K. Kitmura, J. Crystal Growth 275 (2005)1935.

[7]. C. Justin Raj, S. Jerome Das, J.Crystal Growth, 304 (2007)191.

[8]. A. S. J.Lucia Rose, P. Selvarajan,S. Perumal, Physica B 406 (2011)412

[9]. Kathleen I. Schaffers,Douglas A. Keszler, Acta Cryst.C49(1993) 1156.

[10]. S. Dhanushkodi, K. Vasantha, P.A.Angeli Mary, Specrochim. Acta.Part A 66 (2007) 637.

[11]. K.C.Bright, T.H.Freeda, Physics B 405 (2010) 3857.

[12]. P.Kalaiselvi, S.Alfred Cecil Raja, N.Vijayan, Optik 124(2013) 6978.

[13]. P.Selvarajan, J. Glorium Arul Raj, S.Perumal, J. Cryst. Growth,311(2009)3835-3840.

[14]. A.S.J. Lucia Rose, P.Selvarajan, S.Perumal, Physica B 406(2011)412-417.

[15]. S.K.Kurtz, T.T.Perry, J.Appl.Phys. 39(1968) 3798.

[16]. Albert N. L.,Keiser. W.E and Szymanski H.A.,IR theory, Practice of Ir Spectroscopy, Plenum press, New York (1973).

[17]. D. Suptiand J.A. Bhattacharyya, Journal of Physical Chemistry B, Vol.115, No.10, pp 2148-2154(2011).

[18]. K.V.Rao, A.Samakula, Journal.Appl.Phys.36. 2031-2038. (1965).

[19]. R.H.Bube, "Phtoconductivity of solids", Wiley, New York, 1981. 